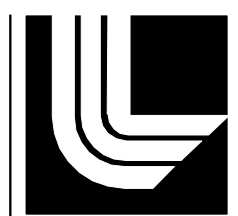

Aftershock Analysis for SPE1

LAWRENCE LIVERMORE NATIONAL LABORATORY

Jerry Sweeney and Phil Harben

November 4, 2011 
This work performed under the auspices of the U.S. Department of Energy by Lawrence Livermore National Laboratory under Contract DE-AC52-07NA27344.

\section{Disclaimer}

This document was prepared as an account of work sponsored by an agency of the United States government. Neither the United States government nor Lawrence Livermore National Security, LLC, nor any of their employees makes any warranty, expressed or implied, or assumes any legal liability or responsibility for the accuracy, completeness, or usefulness of any information, apparatus, product, or process disclosed, or represents that its use would not infringe privately owned rights. Reference herein to any specific commercial product, process, or service by trade name, trademark, manufacturer, or otherwise does not necessarily constitute or imply its endorsement, recommendation, or favoring by the United States government or Lawrence Livermore National Security, LLC. The views and opinions of authors expressed herein do not necessarily state or reflect those of the United States government or Lawrence Livermore National Security, LLC, and shall not be used for advertising or product endorsement purposes. 


\title{
Aftershock Analysis for SPE1
}

\author{
Jerry Sweeney and Phil Harben \\ Lawrence Livermore National Laboratory
}

\section{Introduction}

Aftershock detection and location is an important element of an on-site inspection (OSI) under the Comprehensive Nuclear Test Ban Treaty (CTBT). Aftershocks have been observed to occur in the immediate vicinity of the detonation following nuclear explosions and thus local aftershock monitoring has been included in the CTBT as a method to locate the site of a clandestine underground nuclear test during an OSI. Thus the seismic aftershock monitoring system (SAMS) is an important element of the search procedure during an OSI. Because the frequency of occurrence and magnitude of the aftershocks decay with time following the explosion (Adushkin and Spivak, 1995; Ryall and Savage, 1969), it is important that the inspection be carried out as soon as possible after detection of a suspect event, and this aspect of inspections has been considered in the CTBT Protocol. Because of limited experience with aftershock monitoring, there is large uncertainty about the details of the aftershock process: effects of geology on aftershock rates; effects of initial explosion magnitude on aftershock magnitude; and effects of the seismic source on the distribution of aftershocks in the vicinity of the explosion. Some of these issues have been addressed in recent work (Ford and Walter, 2010; Ford et al, 2011).

The logic in the CTBT concerning aftershock monitoring is that individual aftershocks must be detected, identified, and located in order to determine the location of a suspect underground nuclear test. This approach is highly time dependent, since the inspection team needs to deploy the SAMS soon enough to detect aftershocks before the rate decays to background. One thing that has not been explored is the possibility that a zone of aftershock activity can be detected via elevated seismic noise in the region after the level of aftershocks has decayed to the point where individual events cannot be identified. If this approach - looking for elevated seismic noise in a particular frequency band - works, then the time for application of SAMS in an OSI could be extended. The purpose of our aftershock study associated with the Source Physics Experiments (SPE) is to better quantify aftershock decay rates and dependence on explosion yield and to examine this possibility by carrying out seismic monitoring in the immediate vicinity of an underground explosion using seismic data collected for an extended period following the explosive detonation.

The source physics experiment (SPE) provides an opportunity to study aftershock behavior from a series of chemical explosions in granitic and other types of rock. The main objective of the SPE is to provide a better understanding of the seismic 
source term of an explosion and how it couples into elastic waves that propagate to regional distances, but the SPE also provides an opportunity to study aftershocks.

The current seismic data collection plan for the SPE calls for installation of seismometers and accelerometers along several profiles, radiating from ground zero, out to distances of kilometers, with instrument spacing of hundreds to thousands of meters. For the propagation studies of the SPE, only data collected at the time of detonation is needed, but by merely extending the data collection time out to several days, we are able to also use these data for aftershock studies. This report describes the aftershock data collection that took place during and after the first SPE explosion that took place on May 3, 2011.

\section{Experiment layout, data collection, and results}

We analyzed one week of continuous data immediately following the explosion for the presence of aftershocks. One hour of waveform data was visually examined from three instrument deployment lines (L1, L2, and L4, as shown below), comparing the vertical geophone stations ( 9 waveforms total) located 100, 200, and 300 meters, respectively, from ground zero. Time coincident arrivals on the three lines at the same ranges with a consistent time delay from the $100 \mathrm{~m}$ ring to the $200 \mathrm{~m}$ and $300 \mathrm{~m}$ ring would be highly indicative of an aftershock near the SPE1 working point. We did not observe any patterns fitting these criteria and we conclude that the SPE1 did not produce detectable aftershocks during the recording times available.
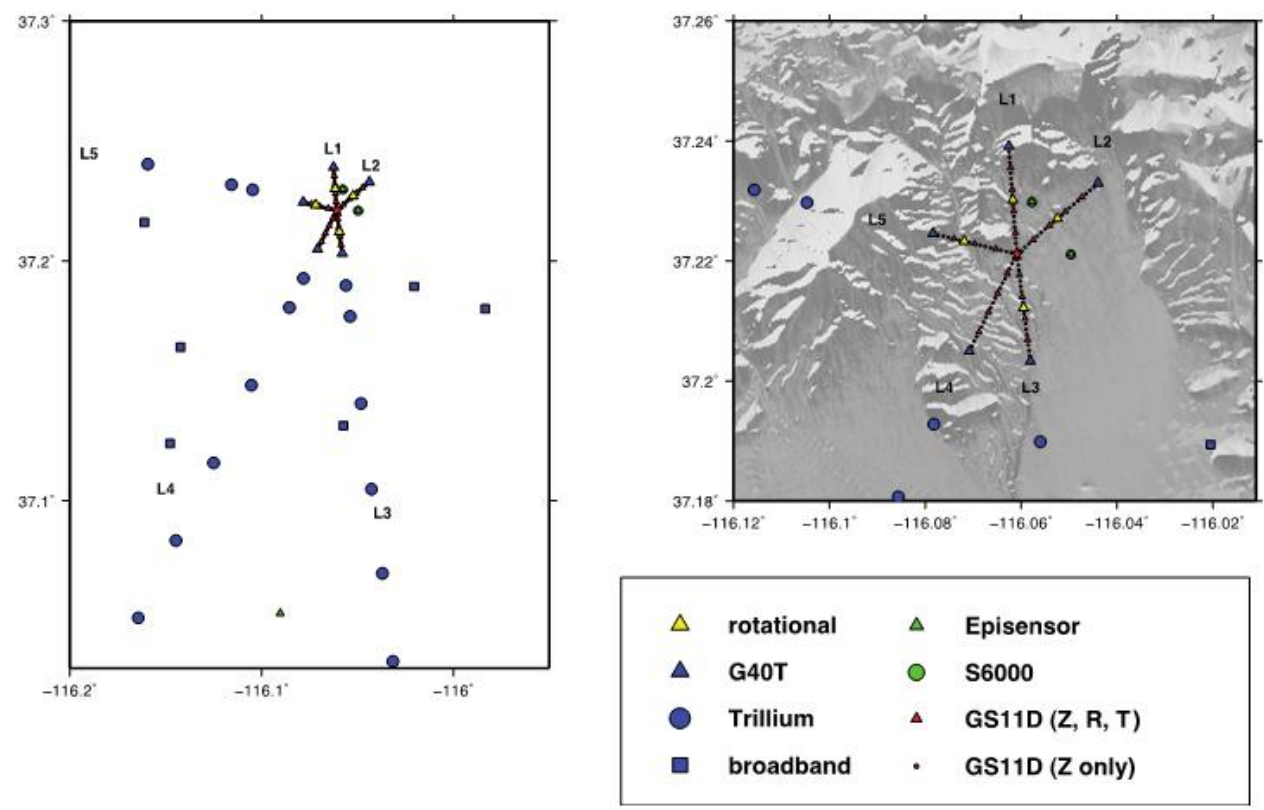

The above figure shows the layout of seismic instrumentation for the first SPE explosion, SPE1. There are lines of instruments radiating out from the center point, which is the hypocenter (ground zero) of SPE1. Aftershock recordings were analyzed for the closest stations on lines L1, L2, and L3. 
This result is more or less consistent with expectations. The plot below assumes the SPE1 explosion to be a magnitude 1.2 event, based on the amount of explosive used. The plot shows the probability of detecting an aftershock at a particular magnitude level (colored lines) as a function of time in days after the explosion. Clearly, after the first day the probability of detection does not change very much, hence the best chance to detect an aftershock is within the first day after the main event. The plot also shows that at the particular distance for each instrument there would need to be a detection sensitivity of magnitude -1.0 in order to have a $50 \%$ probability of detecting an aftershock within the first two days of the explosion. It would appear that the instruments for the data examined here have a detection threshold higher than magnitude -1.0 or zero, since we did not observe any aftershocks.

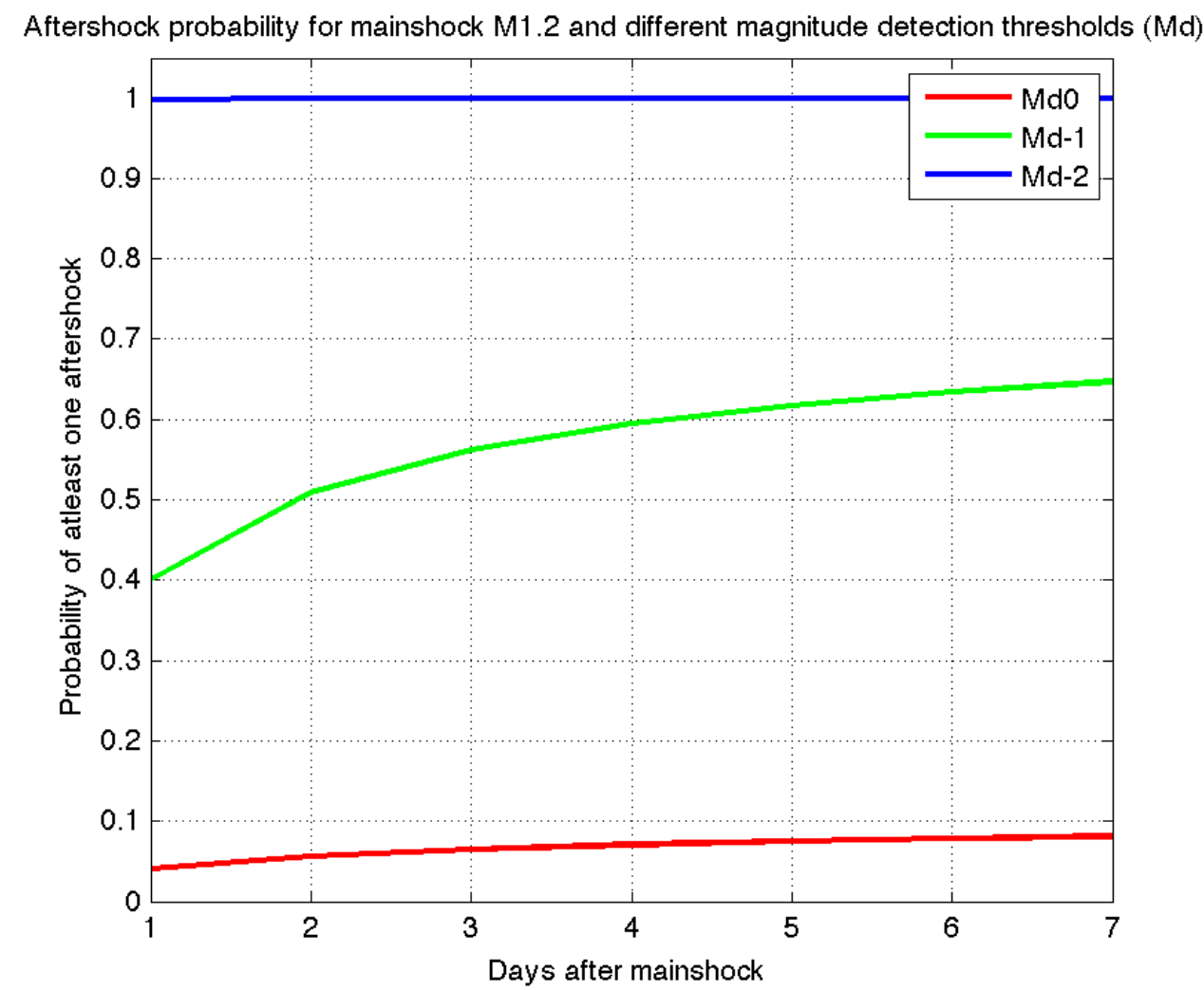

Plot showing the probability of detecting at least one aftershock at a given magnitude threshold following a magnitude 1.2 explosion in hard rock. Plot provided by Sean Ford of LLNL.

The first 12 hours of continuous recordings after SPE1 are shown in the following plots. The first plot shows day 123, hour 23 for the $100 \mathrm{~m}$ vertical geophones on each of the five lines. The plot below that shows the next hour of data and so on. The last plot is for day 124 , hour 10 . Of note is the L3 geophone, which is very noisy and with numerous glitches almost all of the time. This sensor was not utilized in the visual screening for aftershocks. 


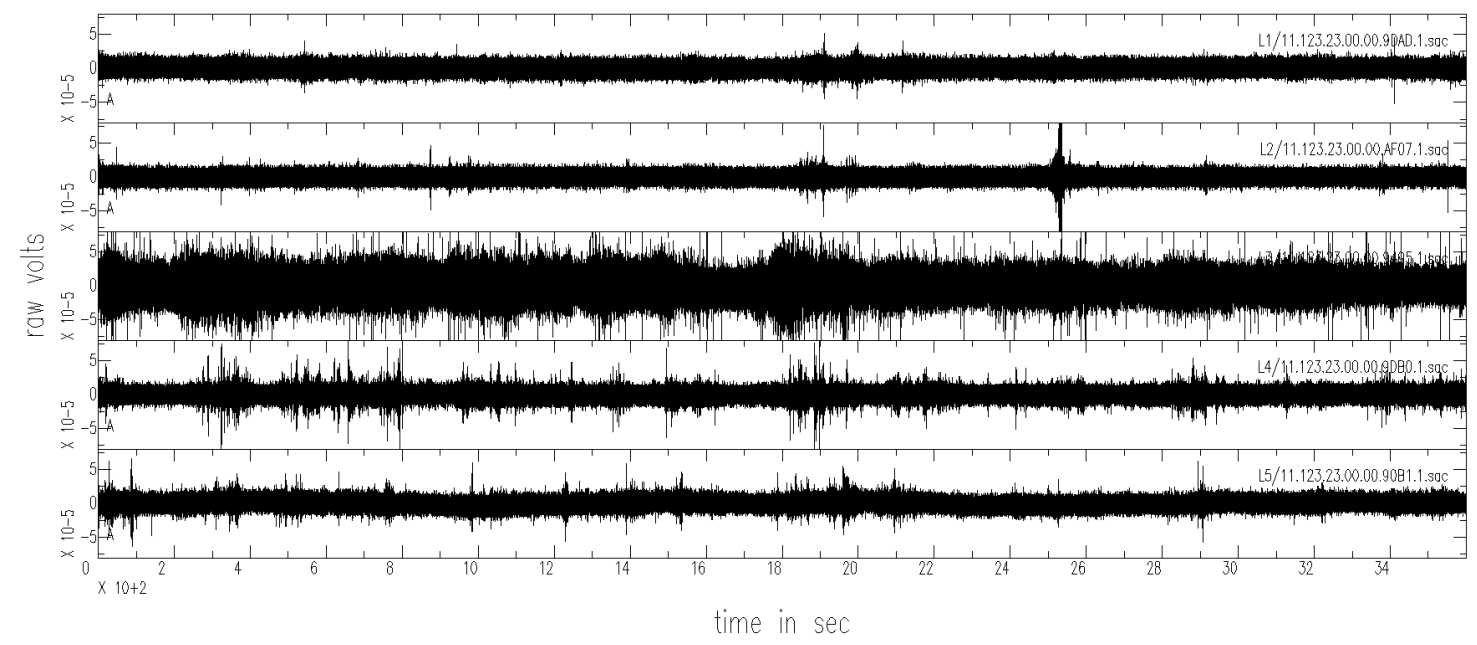

The first hour of data recorded following SPE1 at each (top to bottom) 100 meter geophone location for lines L1 through L5, respectively.

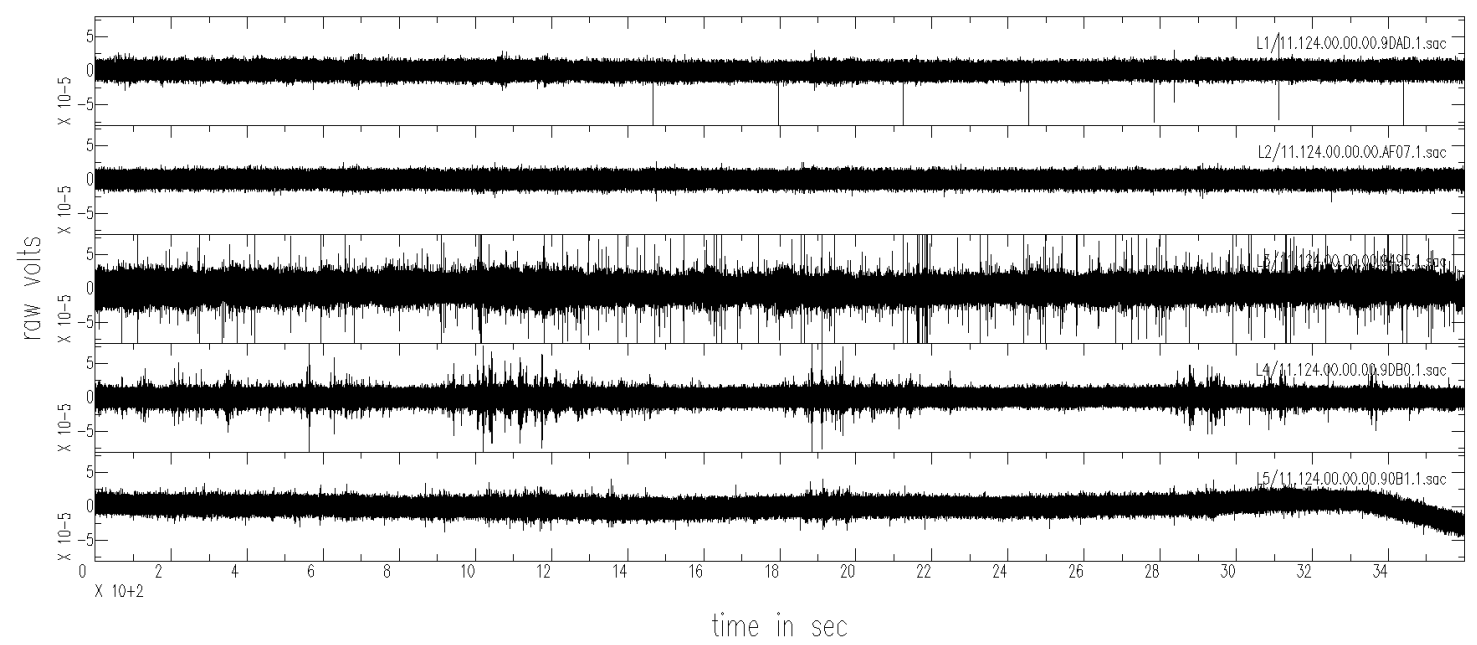

The second hour of data recorded following SPE1 at each (top to bottom) 100 meter geophone location for lines L1 through L5, respectively. 


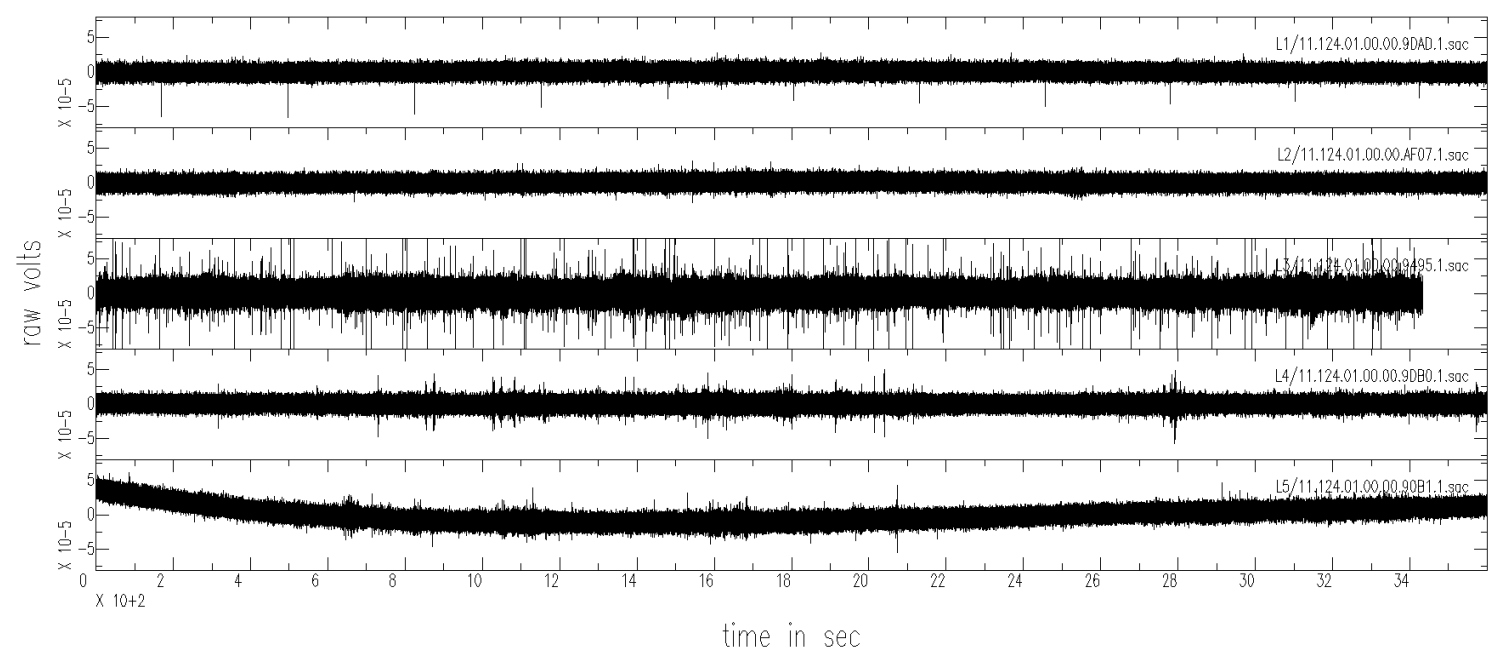

The third hour of data recorded following SPE1 at each (top to bottom) 100 meter geophone location for lines L1 through L5, respectively.

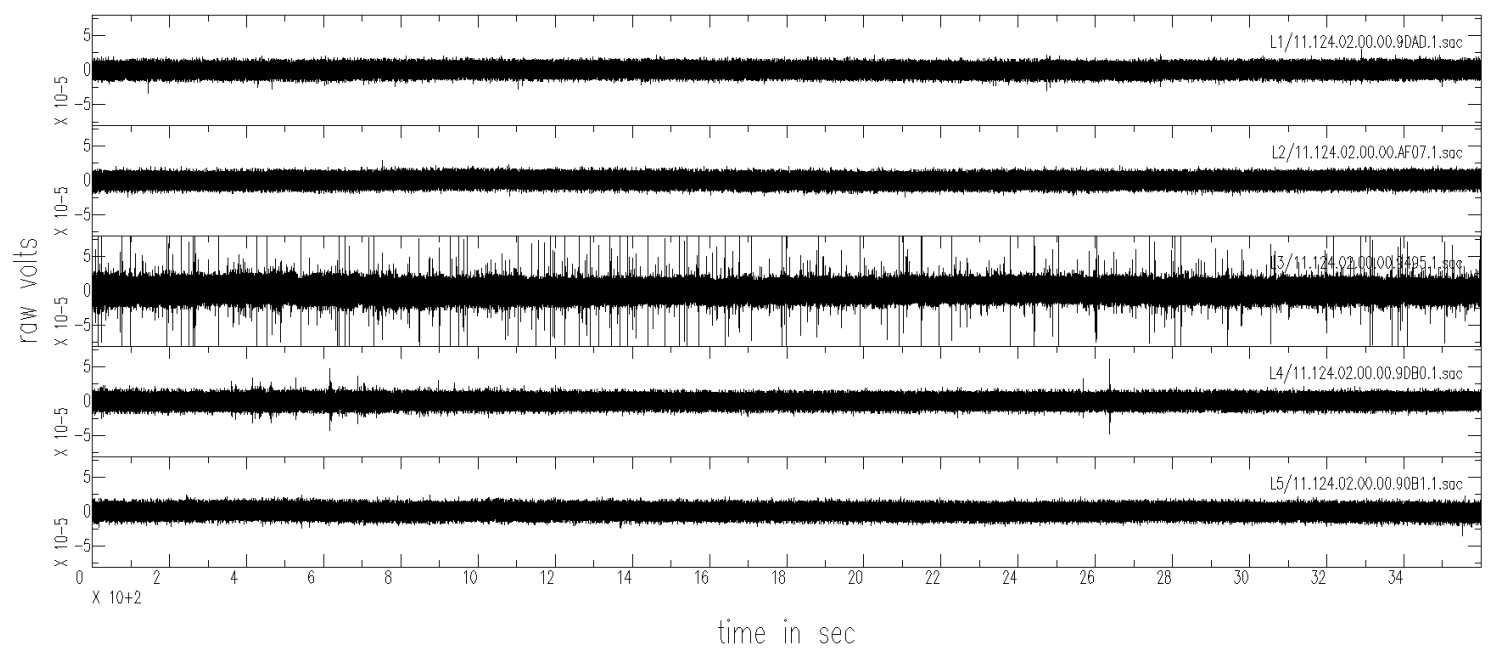

The fourth hour of data recorded following SPE1 at each (top to bottom) 100 meter geophone location for lines L1 through L5, respectively. 


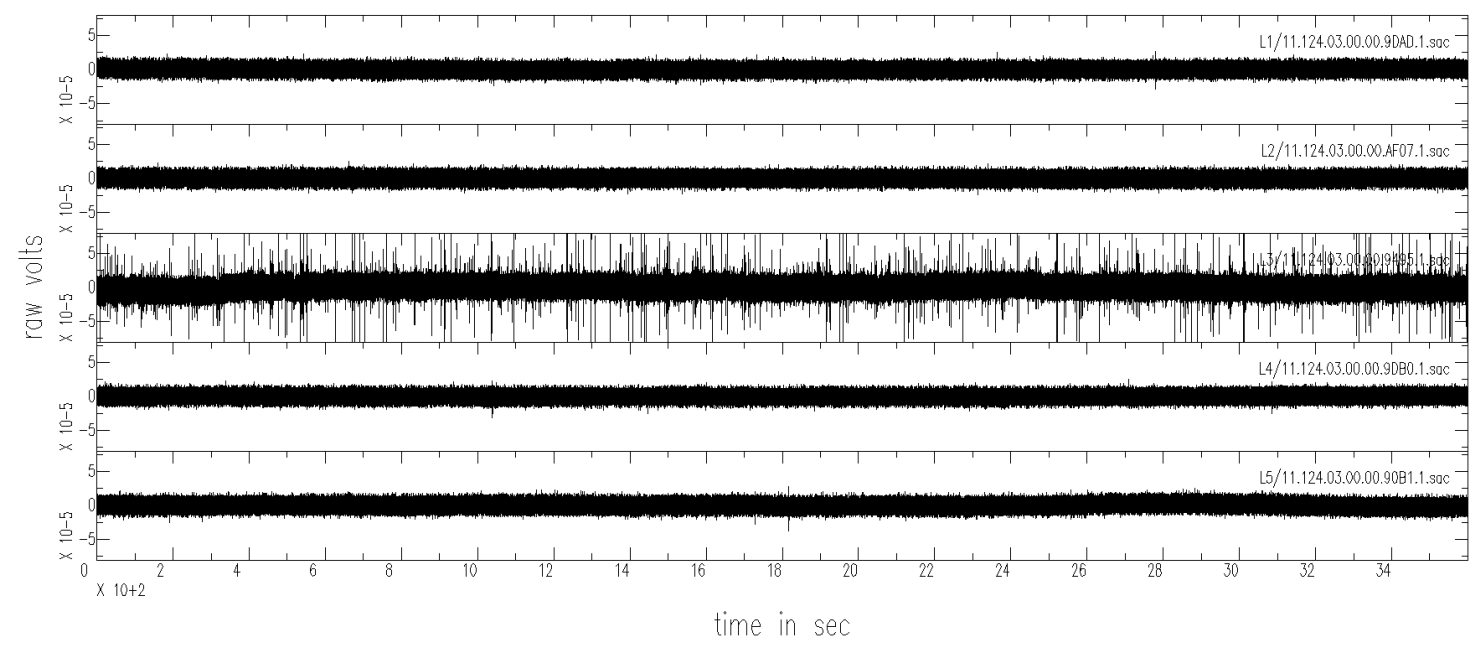

The fifth hour of data recorded following SPE1 at each (top to bottom) 100 meter geophone location for lines L1 through L5, respectively.

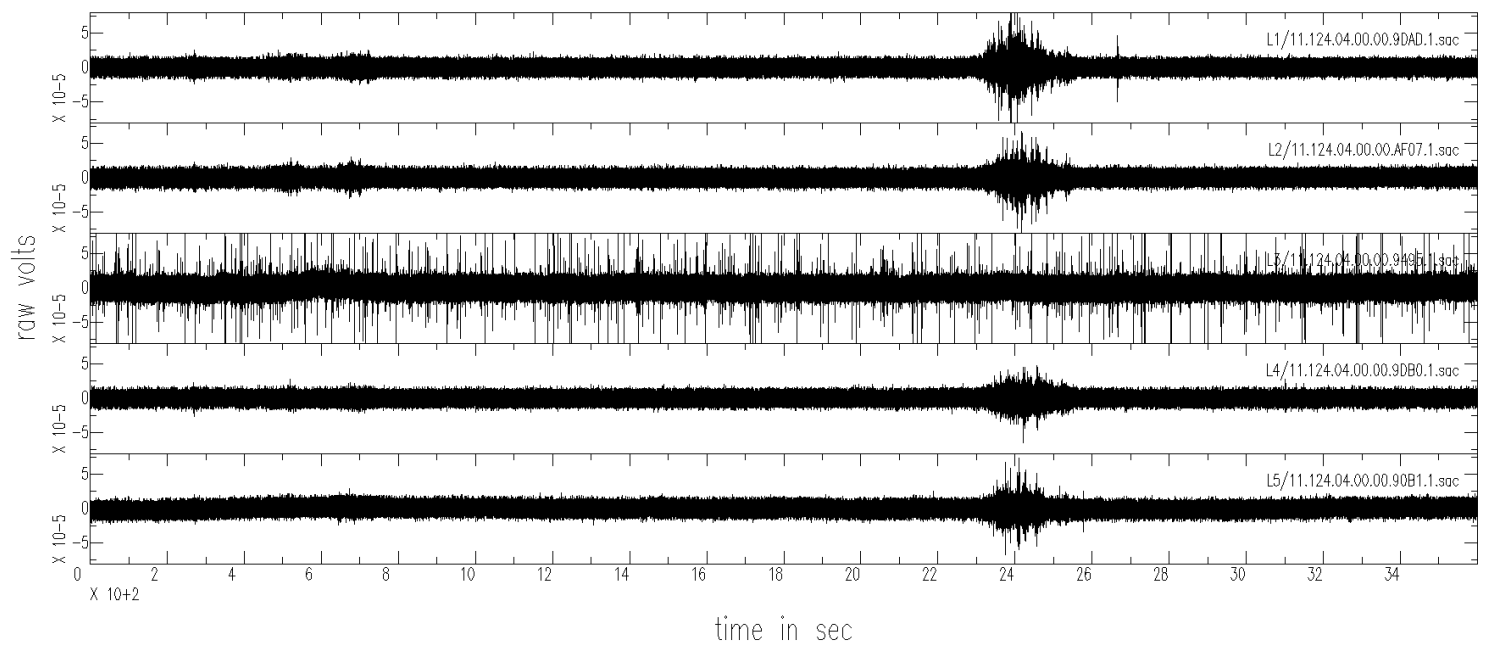

The sixth hour of data recorded following SPE1 at each (top to bottom) 100 meter geophone location for lines L1 through L5, respectively. 


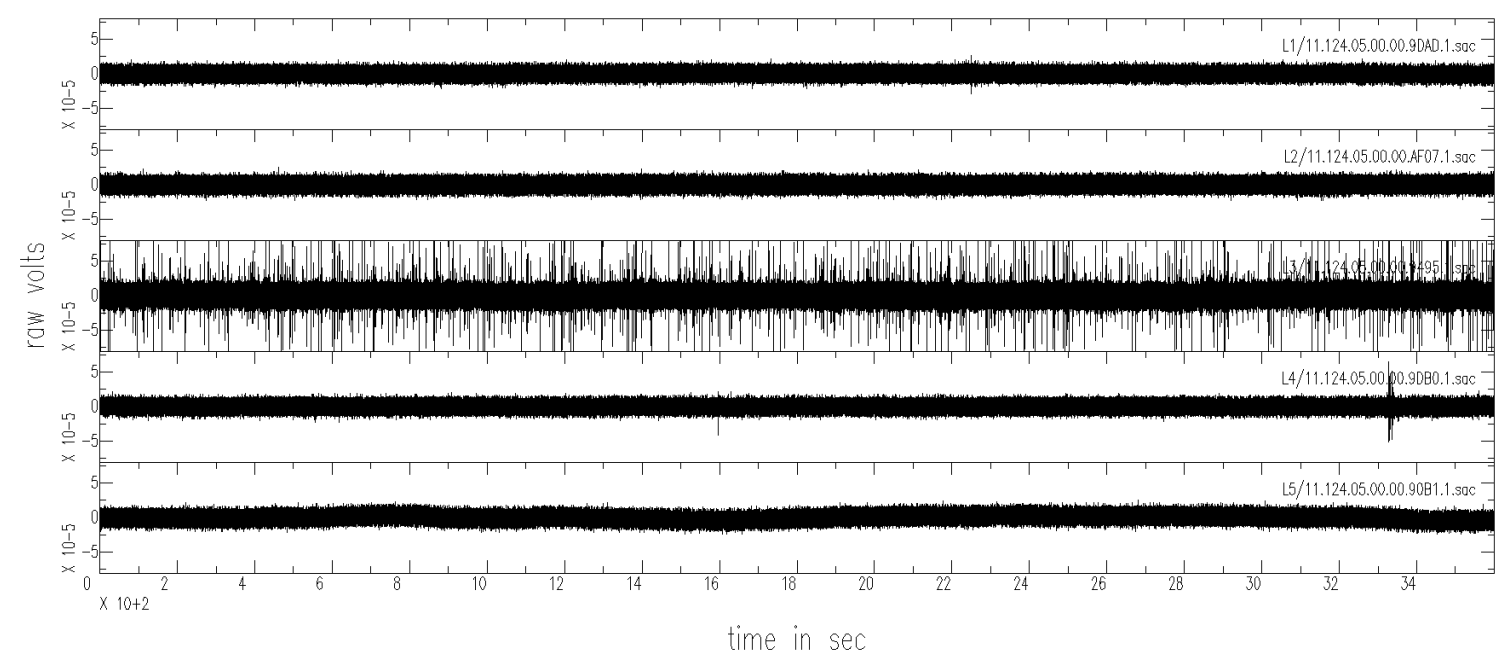

The seventh hour of data recorded following SPE1 at each (top to bottom) 100 meter geophone location for lines L1 through L5, respectively.

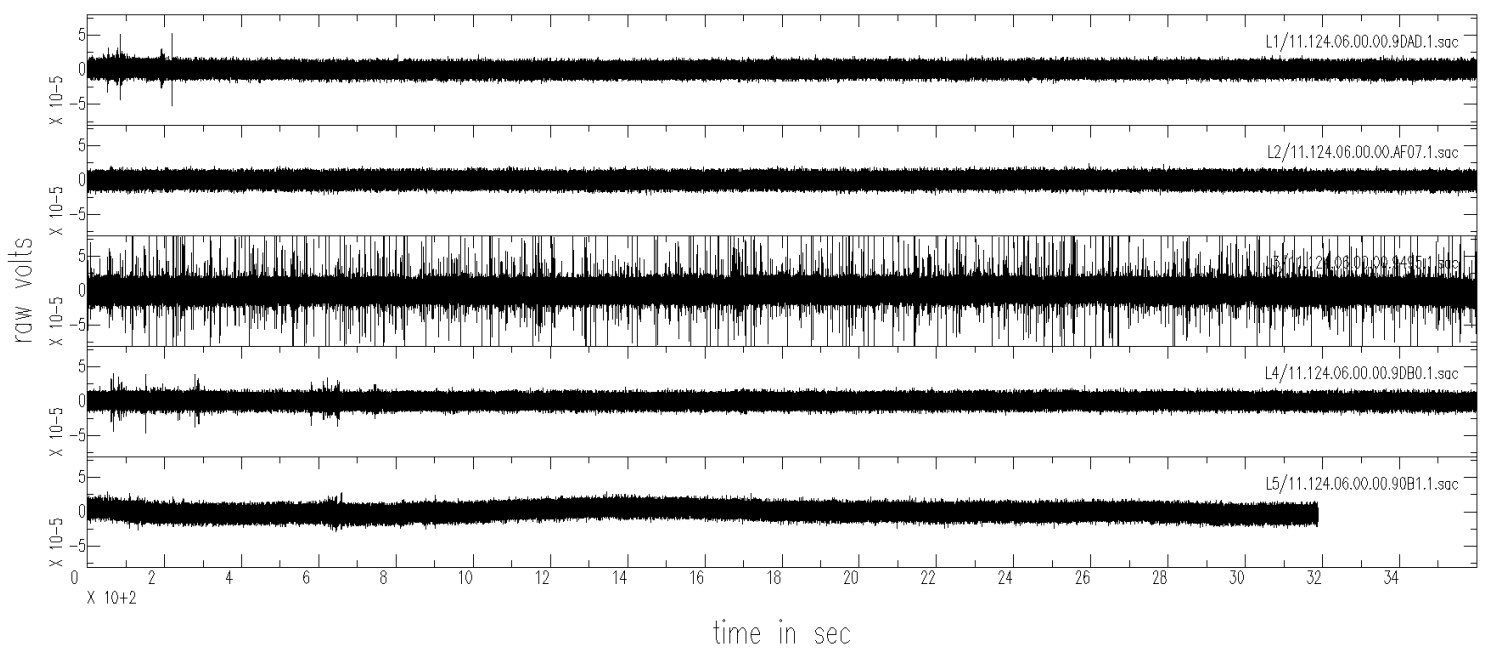

The eighth hour of data recorded following SPE1 at each (top to bottom) 100 meter geophone location for lines L1 through L5, respectively. 


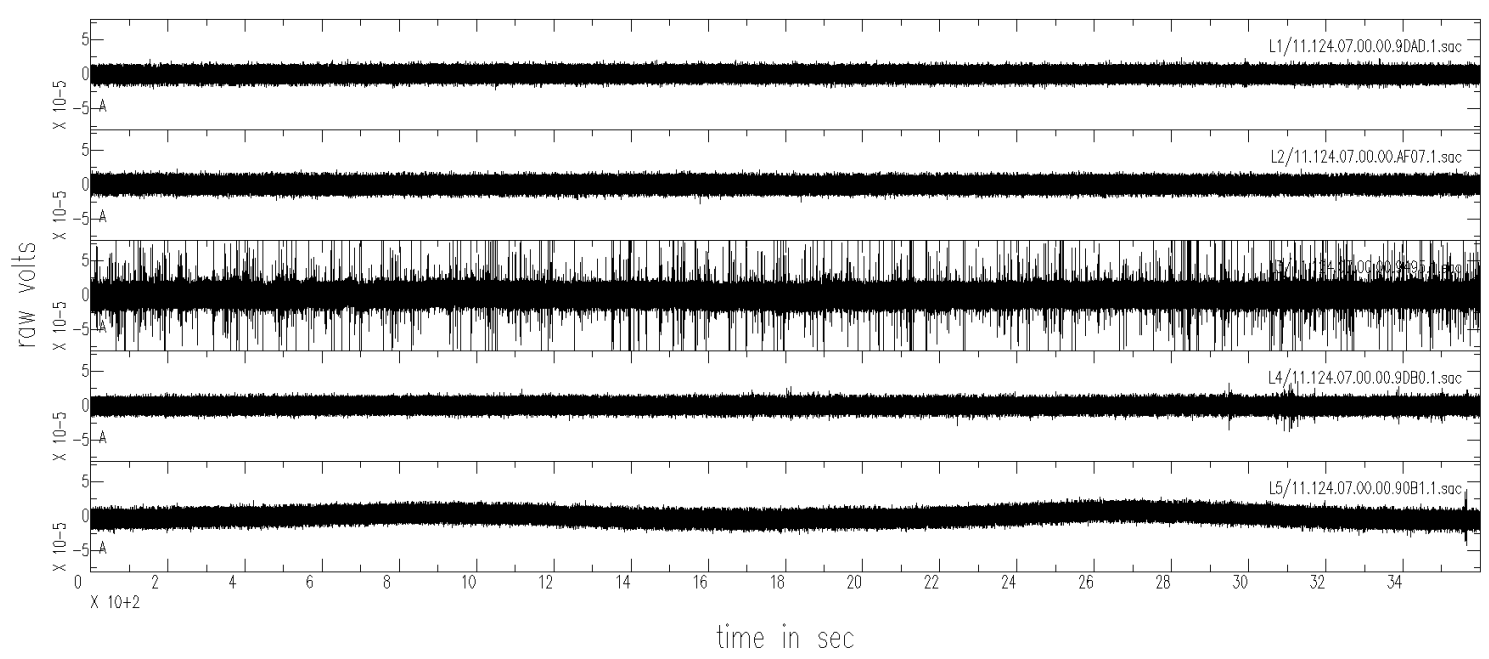

The ninth hour of data recorded following SPE1 at each (top to bottom) 100 meter geophone location for lines L1 through L5, respectively.

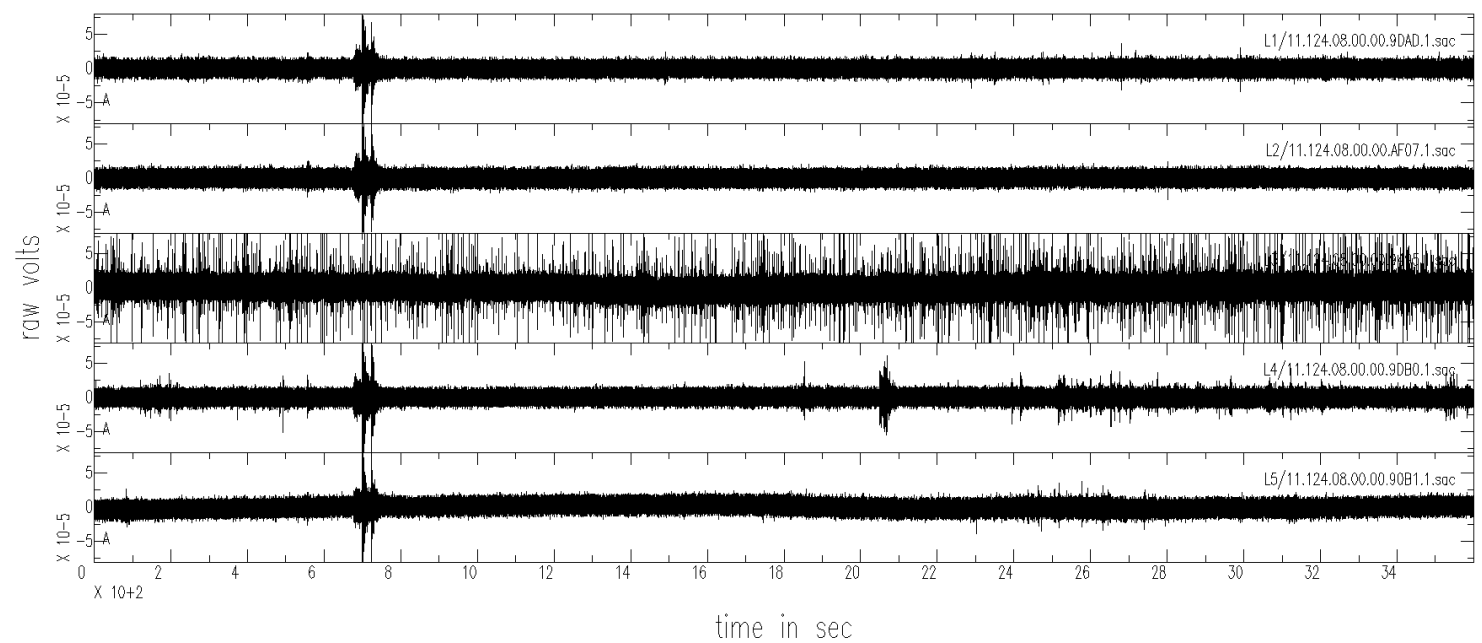

The tenth hour of data recorded following SPE1 at each (top to bottom) 100 meter geophone location for lines L1 through L5, respectively. 


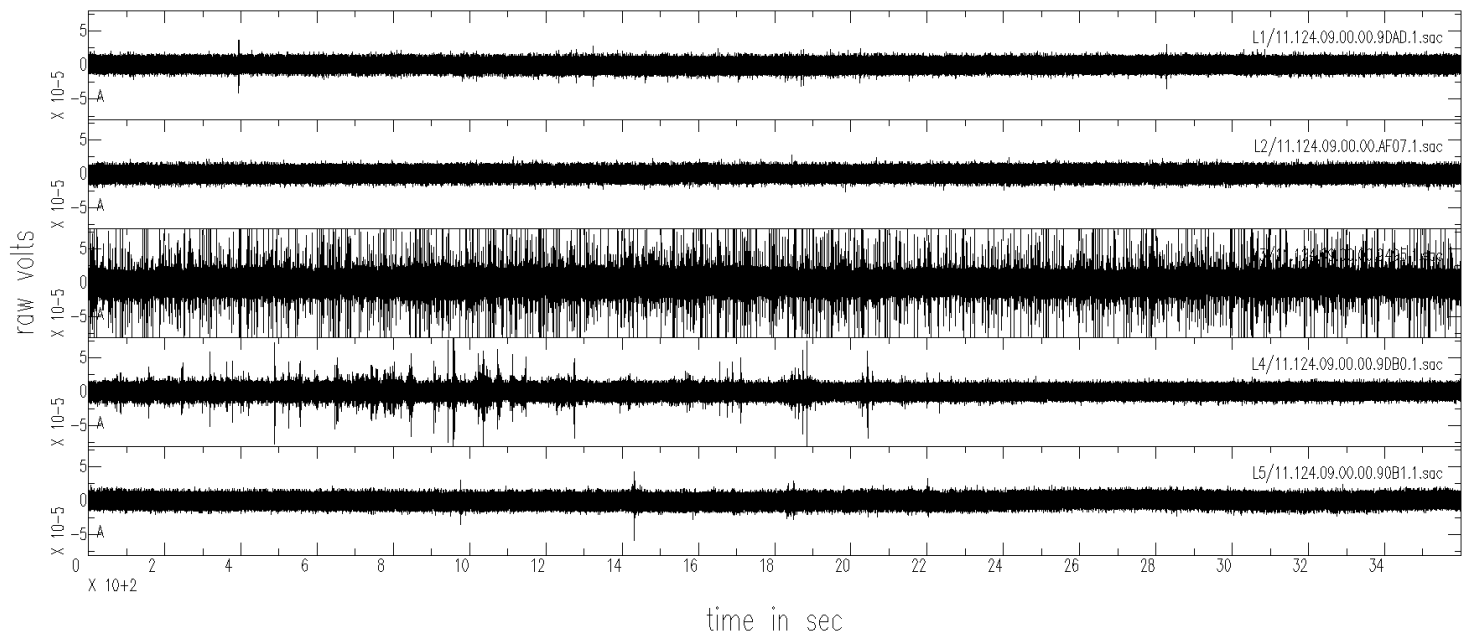

The eleventh hour of data recorded following SPE1 at each (top to bottom) 100 meter geophone location for lines L1 through L5, respectively.

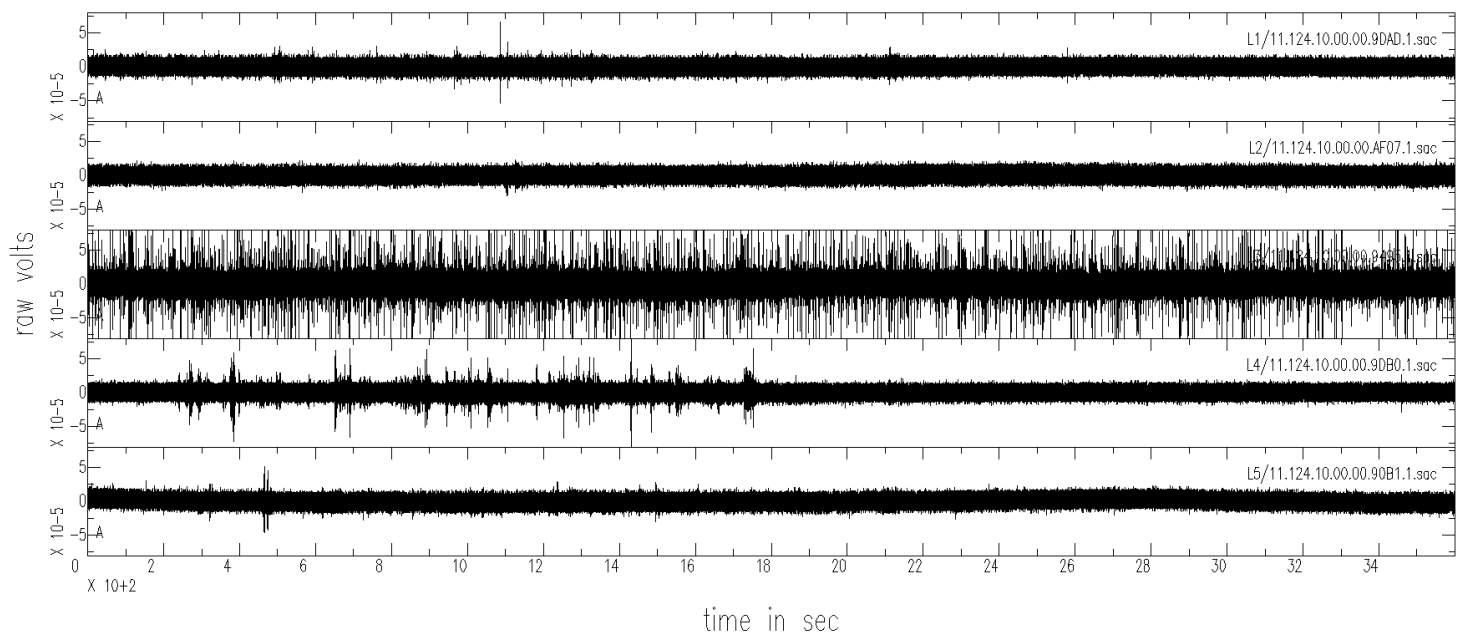

The twelfth hour of data recorded following SPE1 at each (top to bottom) 100 meter geophone location for lines L1 through L5, respectively.

The geophone at 100 meters distance along line L3 seems to be particularly noisy and the one on line L5 has some low frequency drift. The only two plots that are suggestive of possible aftershocks are those for the sixth and tenth hours following the explosion. These are events are several seconds in duration and are regional. Aftershocks from the SPE1 would have durations of only a few seconds at most. 


\section{Conclusions and future plans}

One observation made by others who examined the SPE1 seismic data is that the closest geophones were not well coupled to the ground. The prompt explosion signals at these geophones show strong evidence of local site effects (e.g. the geophone did not closely track the seismic signal because it lost direct contact with the ground). Another observation was that signal cables from six separate instruments were connected via a very simple connecting strip; this would tend to enhance noise and cross coupling between instruments. Both of these effects could have combined to add to the noise levels observed at the geophones used for aftershock monitoring and thus raise the detection threshold dramatically. This is probably the reason why we did not detect aftershocks from SPE1. The cable connection issues have been resolved in preparation for the SPE2 shot.

The SAMS system currently being developed by the OSI Division of the CTBT Organization is designed to have a detection capability of magnitude -2.0 within a range of 2-5 kilometers. That system may be capable of detecting aftershocks from an event like SPE1.

The SPE2 explosion, currently scheduled for late October 2011, will be about 10 times larger in yield than SPE1. New cable junction systems will be used for the geophones, and the instruments will be mounted in the ground with much better coupling for the next explosion. These factors should all combine to make the chances for detecting aftershocks following SPE2 much better.

\section{Acknowledgements:}

We thank Rob Mellors for the instrument layout diagrams and Sean Ford for the aftershock probability estimates and plot.

\section{References:}

Adushkin, V. and A. Spivak, 1995, Aftershock of underground nuclear explosion, in Earthquakes Induced by Underground Nuclear Explosions: Environmental and Ecological Problems, NATO ASI Series: Series 2, Environment, R. Console and A. Nikolaev (Editors), 4, 35-49.

Ford, S., P. Labak, G. Leonard, A. Smith, and J. Sweeney, 2011, The use of explosion aftershock probabilities for on-site inspection planning, deployment, and reporting, (Abstract) Science and Technology 2011 Conference, Comprehensive Nuclear Test Ban Treaty Organization, June 8-10, 2011, Vienna, Austria.

Ford, S. R., and W. R. Walter (2010) Aftershock characteristics as a means of discriminating explosions from earthquakes, Bull. Seis. Soc. Amer., 100 (1) 364-376, doi: 10.1785/0120080349. 
Ryall, A. and W. U. Savage, 1969, A comparisonof seismological effects for the Nevada underground test BOXCAR with natural earthquakes in the Nevada region, J. Geophys. Res., 24, 4281-4289. 